\title{
Solubility of phenylboronic compounds in water
}

\author{
Paweł Leszczyński and Andrzej Sporzyński * \\ Faculty of Chemistry, Warsaw University of Technology, Noakowskiego 3, 00-664 Warsaw, Poland
}

\begin{abstract}
Solubility of six phenylboronic compounds in water was investigated using different methods. The results are consistent with each other, although for particular compounds selected methods should be preferred. The solubility of the investigated compounds is low, with the value of ca. $2 \mathrm{~g} / 100 \mathrm{~cm}^{3} \mathrm{H}_{2} \mathrm{O}$ at $20^{\circ} \mathrm{C}$ for unsubstituted phenylboronic acid. The unsubstituted benzoxaborole is less soluble than phenylboronic acid. Introduction of $\mathrm{OiBu}, \mathrm{COOH}$ and $\mathrm{CF}_{3}$ groups into the phenyl ring decreases solubility in comparison with unsubstituted phenylboronic acid, especially for the alkoxy substituent.
\end{abstract}

Keywords: Solubility, solid-liquid equilibrium, boronic, phenylboronic acid, benzoxaborole.

\section{Introduction}

Boronic acids are the compounds of growing interest not only for Suzuki coupling reaction ${ }^{1}$, but also due to their wide applications in catalysis, medicine and biology ${ }^{2}$. A great interest has been also paid to the supramolecular systems formed by these compounds in which two hydroxyl groups can be involved in various homomeric and heteromeric hydrogen-bonded assemblies, leading to the important compounds applied in materials' chemistry ${ }^{3}$. Recently, rising research activity was directed to benzoxaboroles, internal hemiesters of phenylboronic acids, due to their exceptional properties leading to new applications in biology, medicine and materials' chemistry ${ }^{4}$.

The solubility data are crucial for purification and formulation of new biologically active compounds. Many important reactions require the choice of the right solvent and reaction conditions, especially temperature. Suzuki-Miyaura crosscoupling is the most widely used protocol for the formation of the carbon-carbon bond and has become significant method in the synthesis of biaryl compounds, resulting in a wide range of pharmaceuticals. Among the various sustainable media, water is an attractive solvent for this reaction due to its low cost, non-flammability, non-toxicity, and environment friendliness ${ }^{5}$.

Taking into account the above-mentioned numerous applications of boronic compounds, there are surprisingly few results of their solubility in water and organic solvents. Even for the known for about 150 years phenylboronic acid, only 2 values of its solubility in water at $0^{\circ} \mathrm{C}$ and $25^{\circ} \mathrm{C}$ have been published so far ${ }^{6}$. One can also find some

*Corresponding author: Andrzej Sporzyński

Email address: spor@ch.pw.edu.pl DOI: http://dx.doi.org/10.13171/mjc65/01711030630-sporzynski generalized and misleading statements in the literature such as "boronic acids are water soluble" 5 or "since the reactants are insoluble in water" 7 . For benzoxaboroles there are even less information: only general statement like "[benzoxaboroles] show a better solubility profile "without any data given ${ }^{8}$.

The aim of the present work is to investigate the solubility of boronic acids and benzoxaboroles in water. Since our earlier research on the solubility of organoboron compounds in organic solvents ${ }^{9}$ were focused on different systems, it was necessary to find an appropriate method to determine solubility of these classes of compounds in water. The oldest and frequently used dynamic (synthetic) method with the visual detection of crystals' disappearance ${ }^{9 a}$ failed for the investigated systems. Several methods (A C) have been selected and obtained results compared in terms of consistency of obtained data. Advantages and disadvantages of application of the methods in this particular system have been discussed, taking into account possible sources of measurement errors.

\section{Experimental Section}

\section{Materials}

Phenylboronic acid (1) was obtained from Alfa Aesar and was recrystalized from water before use. The following compounds have been synthesized by the procedures described elsewhere: $\mathbf{2}^{10}, \mathbf{4}^{11}$. Compounds 3, 5 and $\mathbf{6}$ have been synthesized from the corresponding aryl bromides according to the typical procedure described in ${ }^{12}$.

\section{Methods of solubility determination \\ Method A. Dynamic method with the use of luminance probe ${ }^{13}$ \\ Received September 27, 2017 \\ Accepted, October 11, 2017 \\ Published November 2, 2017}


Mixture of solute and solvent, prepared by weighing pure components, were heated to dissolve the solid. The measurements were conducted using the apparatus described by Hofman et al. ${ }^{13}$, in which LED was the source of light and luminance was measured using the LP 471 LUM 2 probe (Photo-
Radiometer HD2102.1). Measured temperatures and light intensities were acquired independently and transformed into the light intensity versus temperature dependence. A typical observed dependence noted for the phenylboronic acid + water system is shown in Figure 1.

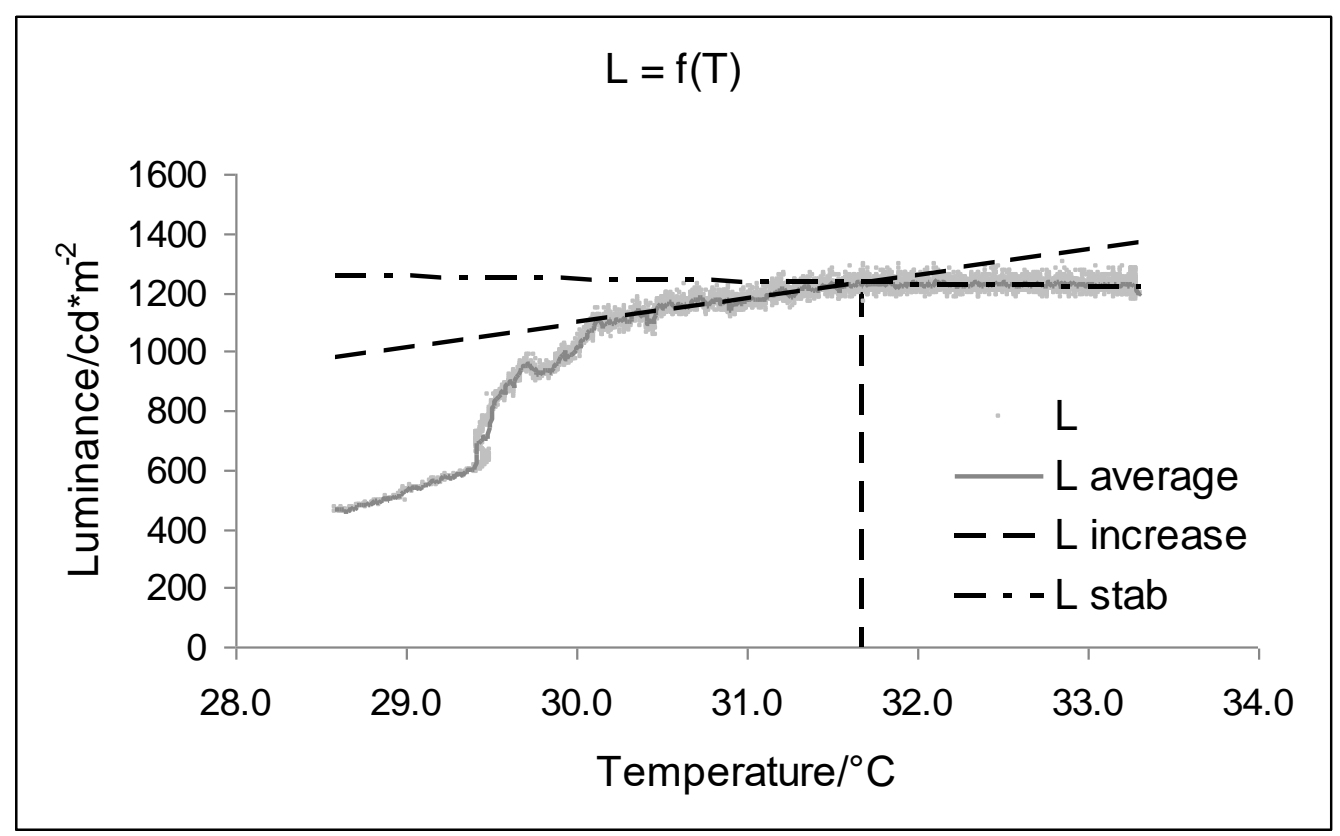

Figure 1. Luminance vs. temperature plot for phenylboronic acid $\mathbf{1}$ in water.

Method B. Conductometric method ${ }^{14}$

The measurements were conducted by the method originally described by Rogalski et al. for determination of solubility of phenols in water ${ }^{14}$. Weighted amounts of the boronic compound and water were placed in the conductivity sample cell. The cell was designed to minimize vapor volume to avoid the partial vaporization at elevated temperatures. The amount of solute was in excess with respect to saturation. The solution was stirred for $2 \mathrm{~h}$ at a temperature sufficiently high to solubilize all of the solute and cooled to precipitate the solute. The mixture was stirred for $2 \mathrm{~h}$ at the measurement temperature before starting conductivity measurements.

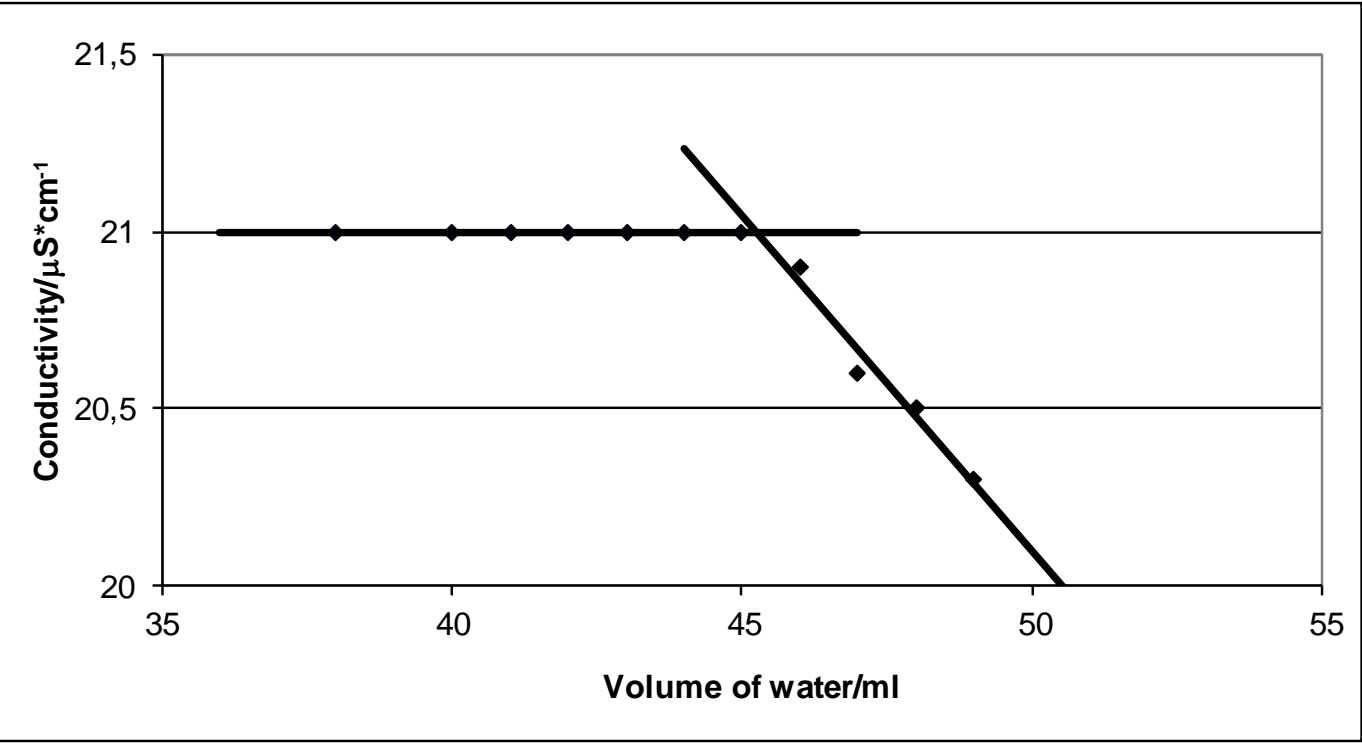

Figure 2. Conductance vs. volume of water plot for the compound 3 at $40^{\circ} \mathrm{C}$. 
The excess solute was dissolved by injecting known volumes of water (from 0.5 to $2.5 \mathrm{~cm}^{3}$ ). After each injection, the solution was vigorously stirred for about $20 \mathrm{~min}$ to ensure thermal and chemical equilibrium. The stirring was stopped before every measurement. Repeated measurements for each added volume allow to check if the equilibrium was reached (the same conductance values for two measurements). Typical plot of conductance vs. volume of the solvent for a constant temperature is shown in Figure 2.
Method C. Isothermal (static) method

The suspension of solute in water was stirred at constant temperature for about $4 \mathrm{~h}$ to reach equilibrium. After sedimentation of the solid a saturated solution was sampled, weighed and evaporated at $90^{\circ} \mathrm{C}$ to reach a constant mass of the solid. For a given temperature, each determination was repeated to obtain similar results. The presented data are the mean values for each temperature.

\section{Results and Discussion}

Solubility of the boronic compounds in water was investigated for the compounds shown in Chart 1.

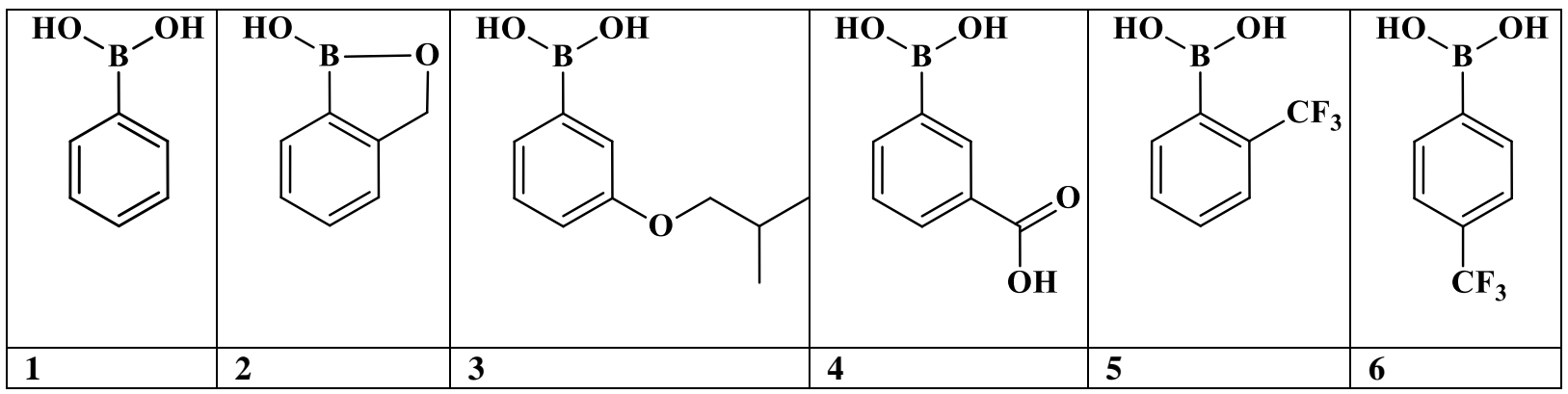

Chart 1. Boronic compounds investigated in the present paper.

Solubility of phenylboronic acid (1) determined by methods A - C is shown in Figure 3.

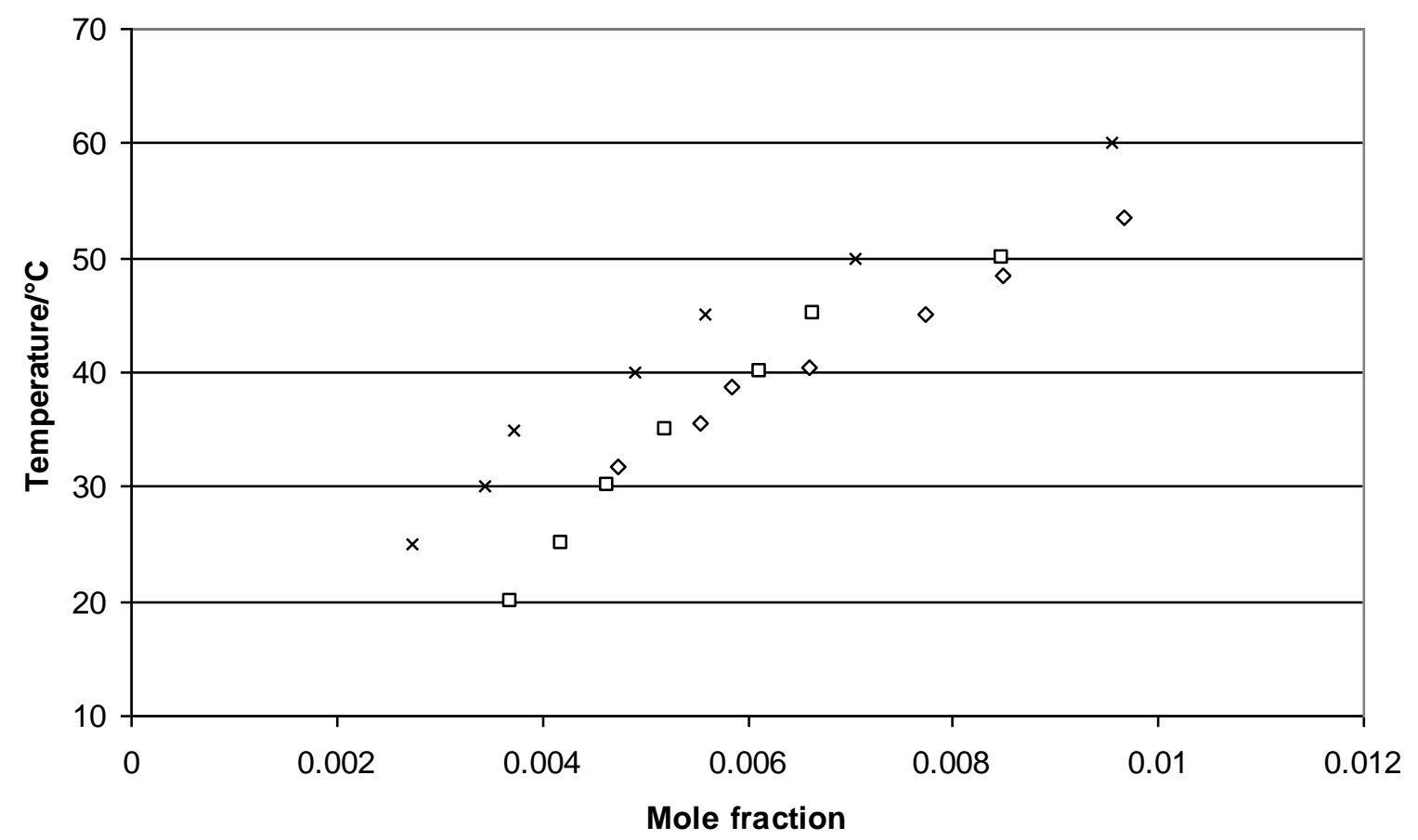

Figure 3. Solubility of phenylboronic acids (1) in water. $\diamond$ Method $\mathbf{A}, \square \operatorname{method} \mathbf{B}, \mathbf{x}$ method $\mathbf{C}$.

Lower values obtained by method $\mathbf{C}$ can be caused by the formation of boroxine during evaporation of the solvent at $90^{\circ} \mathrm{C}$ according to Eq. 1 :

$$
3 \mathrm{PhB}(\mathrm{OH})_{2} \rightarrow(\mathrm{PhBO})_{3}+3 \mathrm{H}_{2} \mathrm{O}
$$

The formation of cyclic anhydrides (boroxines) by boronic acids is a well-known feature of these compounds. The acid/boroxine equilibrium depends on the substituents in the aryl group. DSC measurements of the p-methoxyphenylboronic acid confirm that the fast dehydration starts at about $90^{\circ} \mathrm{C}^{15}$. However, some compounds dehydrate easily during standing on air at room temperature. DSC curve for unsubstituted phenylboronic acid (1) and for the corresponding boroxine is shown in Figure 4. 

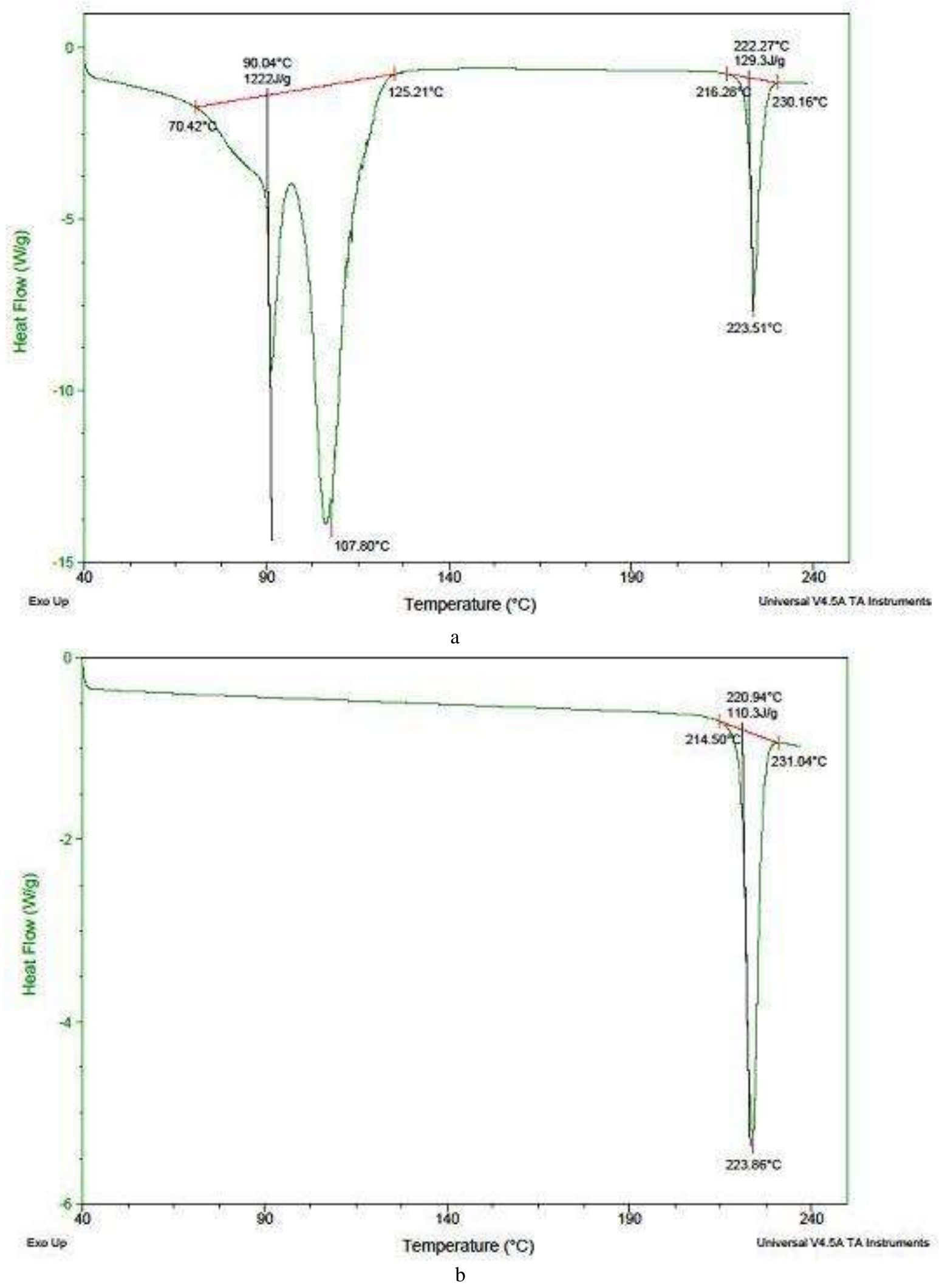

Figure 4. DSC plot for phenylboronic acid (1) (a) and triphenylboroxine (b).

Solubility of benzoxaborole (2) is shown in Figure 5. 


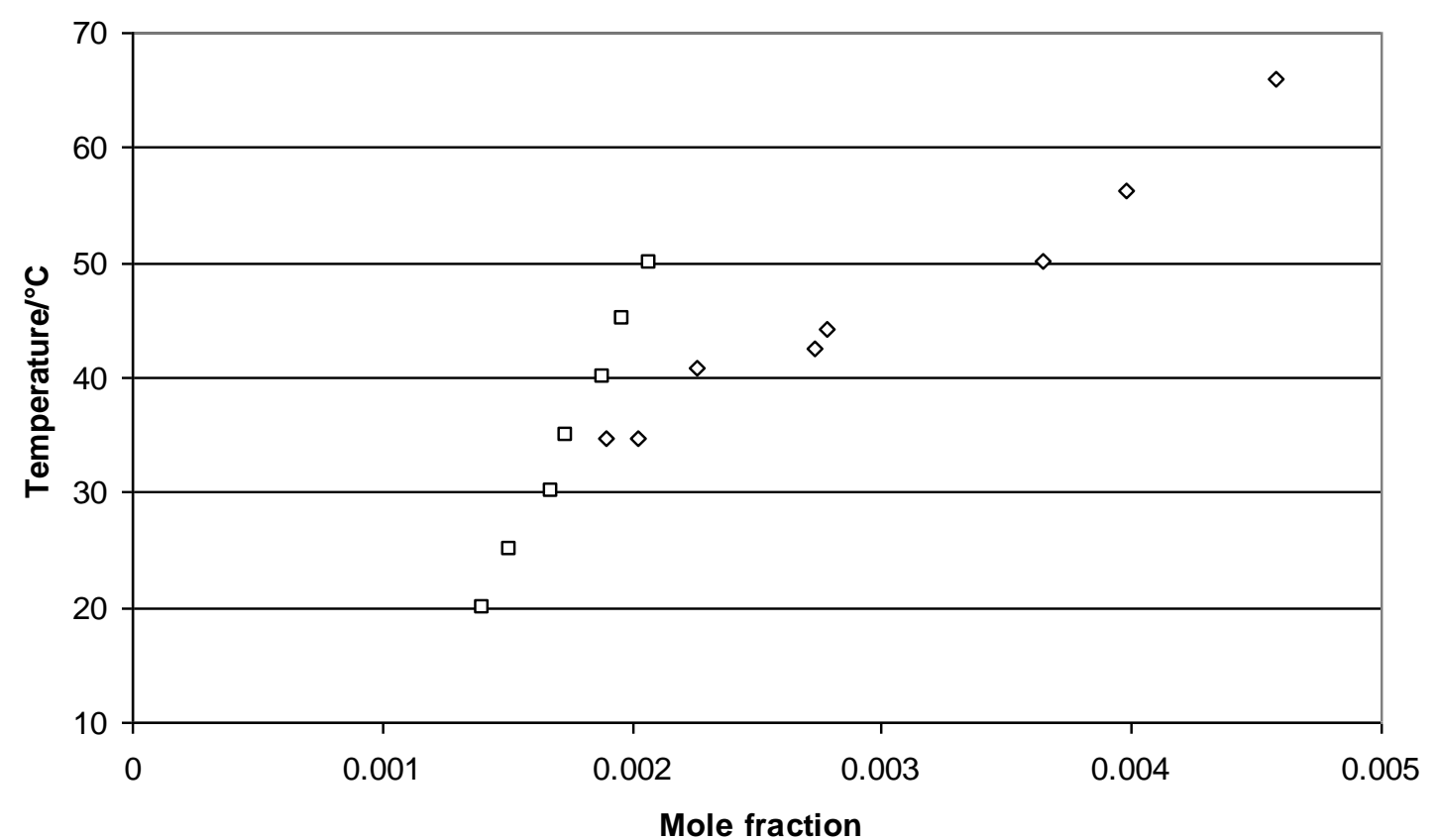

Figure 5. Solubility of benzoxaborole (2) in water. $\diamond$ Method A, $\square \operatorname{method} \mathbf{B}$.

In order to investigate the influence of substituents on the solubility of boronic acids in water we investigated compounds $\mathbf{3}$ - $\mathbf{6}$. The results are shown in Figures. 6 - 9.

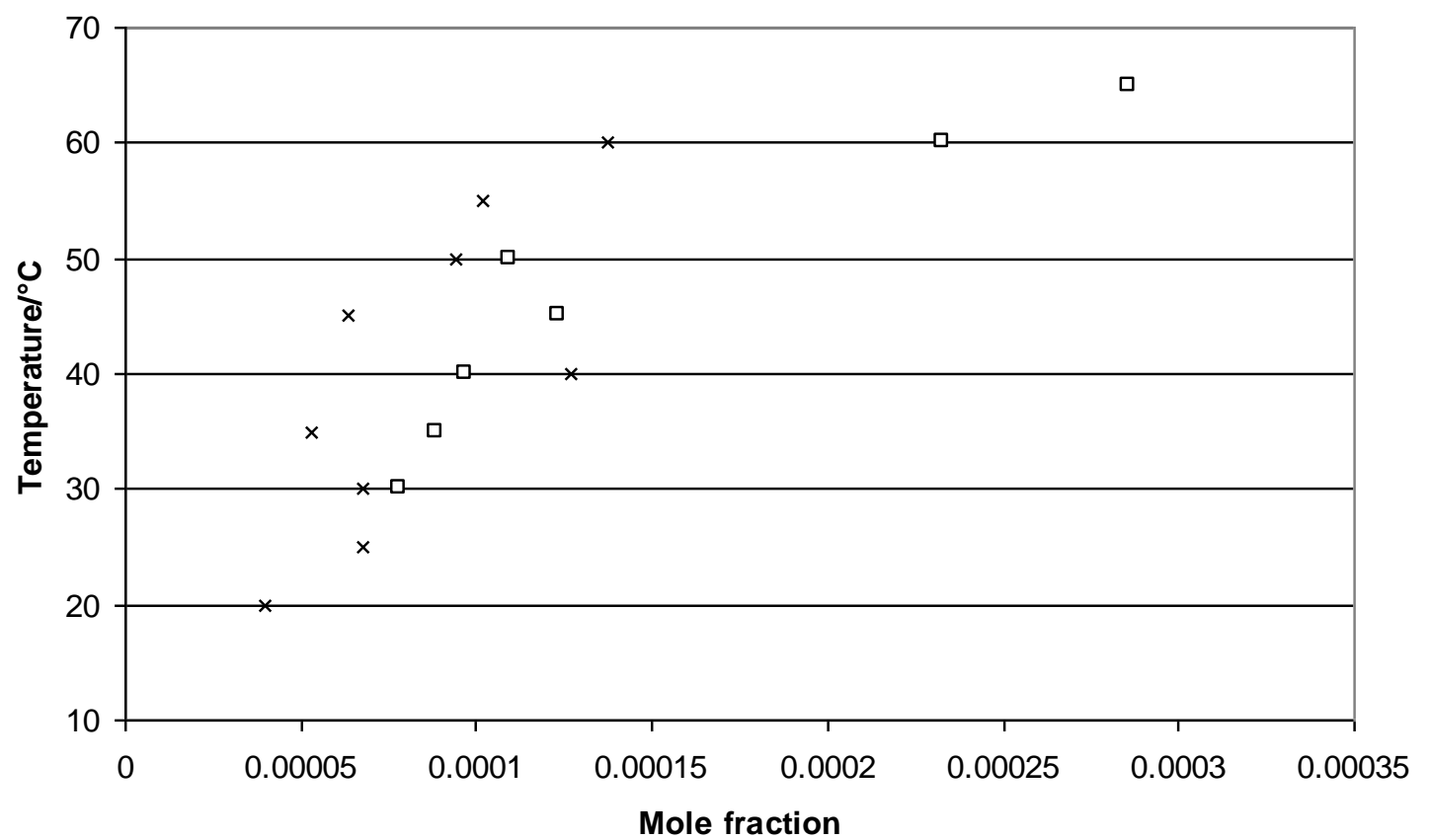

Figure 6. Solubility of 3-isobutoxyphenylboronic acid (3) in water. $\square$ Method $\mathbf{B}, \mathbf{x}$ method $\mathbf{C}$.

Introduction of alkoxy substituent in compound 3 decreases solubility in water. Moreover, a much larger spread of results is visible for this compound, especially applying the method $\mathbf{C}$. The difficulties of solubility determination for this type of compound can be also caused by the possibility of aggregation in aqueous solution into variety of structures like micelles, vesicles, and more complex ones ${ }^{16}$.

Solubility of other compounds $(\mathbf{4}-\mathbf{6})$ in water was determined by the method $\mathbf{C}$. The results are shown in Figures $7-9$. 


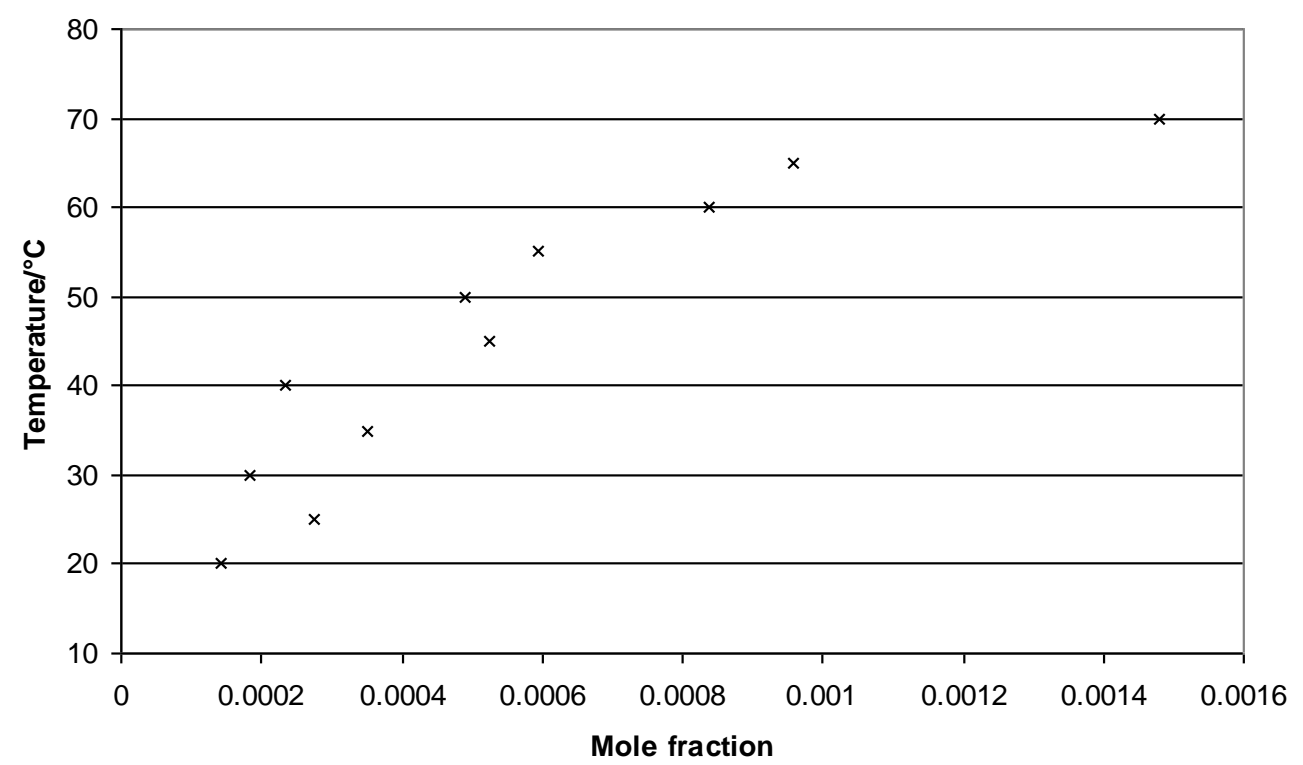

Figure 7. Solubility of 3-carboxyphenylboronic acid (4) in water.

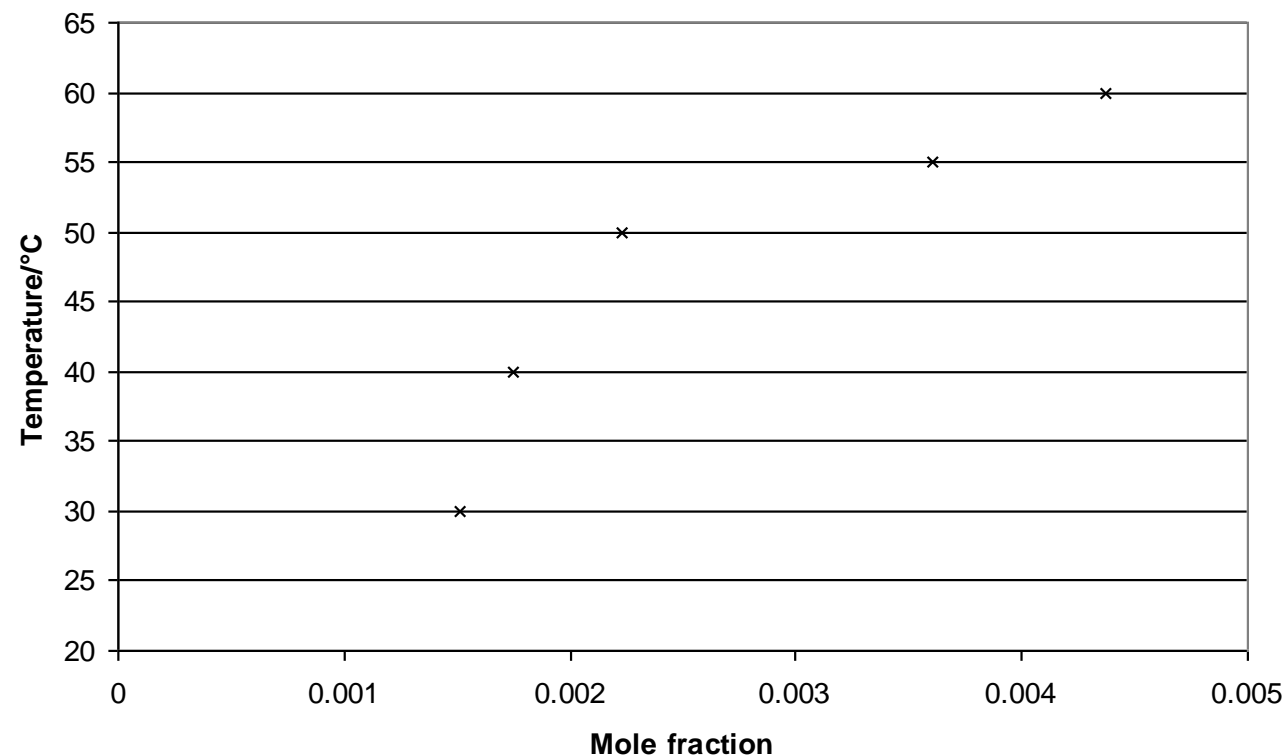

Figure 8. Solubility of 2-(trifluoromethyl)phenylboronic acid (5) in water.

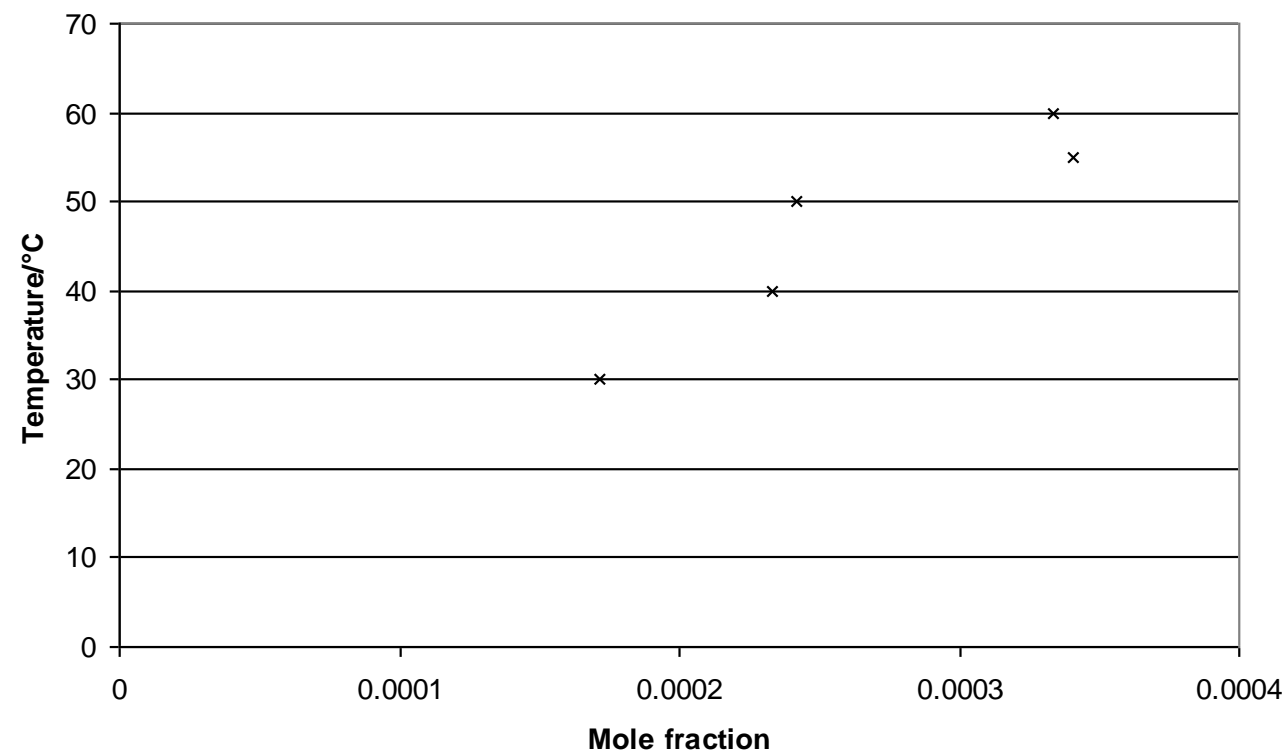

Figure 9. Solubility of 4-(trifluoromethyl)phenylboronic acid (6) in water. 
Comparison of solubility of investigated compounds is shown in Figure 10.

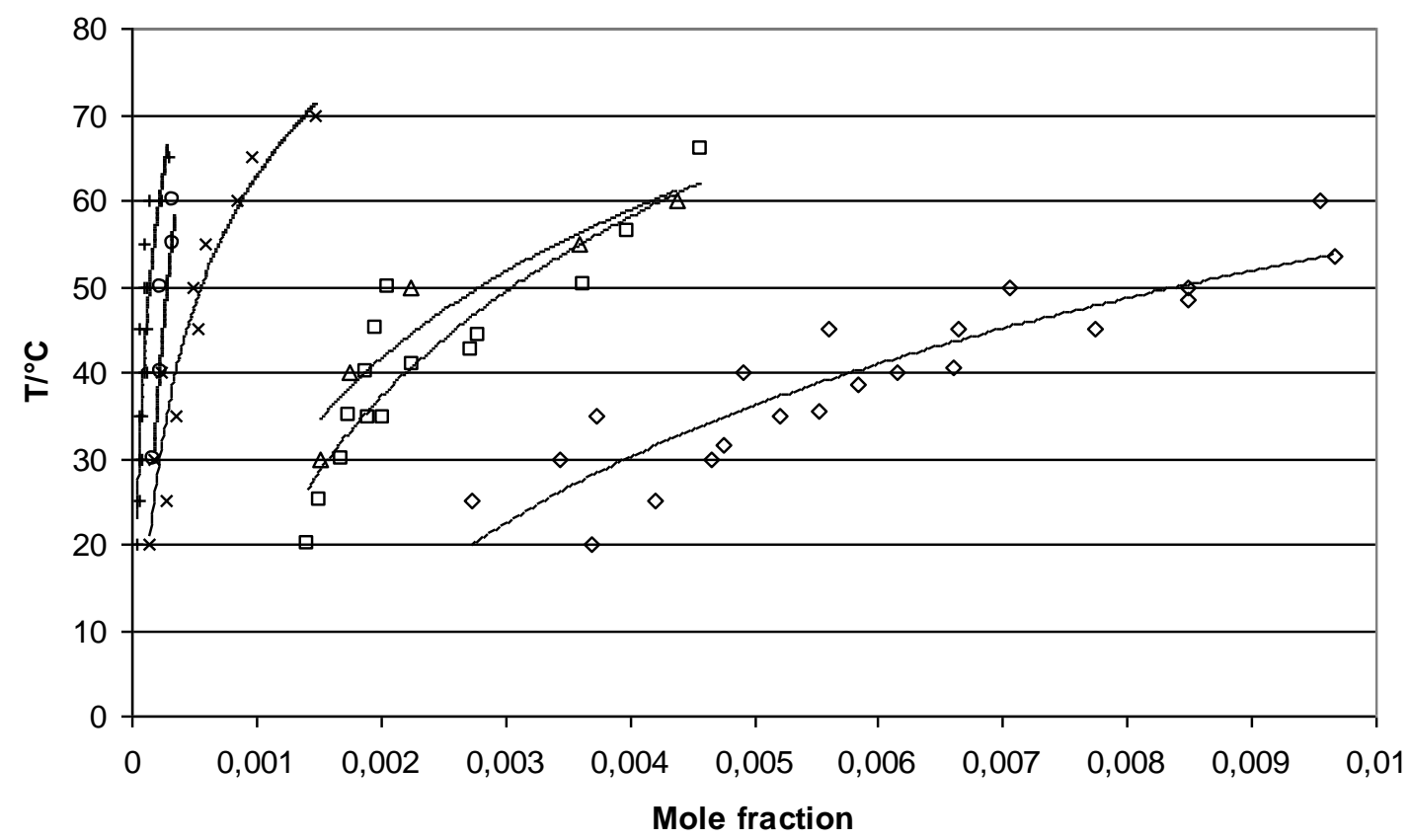

Figure 10. Solubility of investigated compounds in water. $\diamond$ Phenylboronic acid (1), $\square$ benzoxaborole (2), +3 isobutoxyphenylboronic acid (3), x 3-carboxyphenylboronic acid (4), $\Delta 2$-(trifluoromethyl)phenylboronic acid (5), ○ 4-(trifluoromethyl)phenylboronic acid (6). Solid lines represent logarithmic trend lines.

The solubility of investigated compounds in $\mathrm{g} / 100 \mathrm{~g} \mathrm{H}_{2} \mathrm{O}$ at $20.0^{\circ} \mathrm{C}$ and $50.0^{\circ} \mathrm{C}$ is collected in Table 1 .

Table 1. Solubility in water in $\mathrm{g} / 100 \mathrm{~g} \mathrm{H}_{2} \mathrm{O}$ for selected temperatures, calculated from the curves in Figure 10.

\begin{tabular}{|l|l|l|l|}
\hline \multirow{2}{*}{ Compound } & \multicolumn{2}{|l|}{ Temperature $/{ }^{\circ} \mathrm{C}$} & \multirow{2}{*}{$\begin{array}{c}\text { Standard } \\
\text { deviation }\end{array}$} \\
\cline { 2 - 3 } & 20.0 & 50.0 & 0.025 \\
\hline $\mathbf{1}$ & 1.86 & 5.75 & 0.021 \\
\hline $\mathbf{2}$ & 0.84 & 2.27 & 0.0017 \\
\hline $\mathbf{3}$ & 0.04 & 0.15 & 0.0043 \\
\hline $\mathbf{4}$ & 0.13 & 0.51 & 0.0236 \\
\hline $\mathbf{5}$ & 0.80 & 2.67 & 0.0018 \\
\hline $\mathbf{6}$ & 0.12 & 0.26 & \\
\hline
\end{tabular}

All the primary experimental data are collected in Supplementary Data.

\section{Conclusions}

1. All the applied methods of solubility investigations give comparable results. However, the selection of the appropriate method depends on particular compound.

2. Phenylboronic acid (1) shows the best solubility in water. Benzoxaborole (2) is less soluble than $\mathbf{1}$.

3. Introduction of $\mathrm{OiBu}, \mathrm{COOH}$ and $\mathrm{CF}_{3}$ groups causes decrease of solubility in comparison with $\mathbf{1}$.

4. ortho-Isomer of (trifluoromethyl)phenylboronic acid (5) is less soluble than para-isomer 6.

5. Significant change of solubility with temperature allows to use water as crystallization solvent.

\section{Acknowledgement}

This work was supported by Warsaw University of Technology.

\section{References}

1- N. Miyaura and A. Suzuki, Chem. Rev., 1995, 95, 2457-2483.

2- Boronic Acids. Preparation and Applications in Organic Synthesis, Medicine and Materials, second ed., D.G. Hall (Ed.), Wiley-VCH, Weinheim, 2011.

3- S. Sene, M.A. Pizzoccaro, J. Vezzani, M. Reinholdt, P. Gaveau, D. Berthomieu, S. Bégu, C. Gervais, C. Bonhomme, G. Renaudin, A. Mesbah, A. van der Lee, M.E. Smith and D. Laurencin, Crystals, 2016, 6, 48.

4- A. Adamczyk-Woźniak, K.M. Borys and A. Sporzyński, Chem. Rev., 2015, 115, 5224-5247.

5- R.I. Khan and K. Pitchumani, Green Chem., 2016, 18, 5518-5528. 
6- R.M. Washburn, E. Levens, C.F. Albright and F.A. Billig, Org. Synth. Coll. Vol., 1963, Vol. IV, p. 71.

7- H. Firouzabadi, N. Iranpoor, A. Ghaderi, M. Gholinejad, S. Rahimi and S. Jokar, RSC Adv., 2014, 4, 27674-27682.

8- M. Dowlut and D.G. Hall, J. Am. Chem. Soc., 2006, 128, 4226-4227.

9- (a) U. Domańska, J. Serwatowski, A. Sporzyński, M. Dąbrowski, Thermochim.Acta, 1993, 222, 279-290; (b) U. Domańska, J. Serwatowski, A. Sporzyński, M. Dąbrowski, Thermochim. Acta, 1995, 249, 127-142; (c) M. Dąbrowski, U. Domańska, J. Serwatowski, A. Sporzyński, Thermochim. Acta, 1995, 250, 19-27; (d) M. Dąbrowski, J. Serwatowski, A. Sporzyński, Thermochim. Acta, 1996, 288, 191-202; (e) M. Dąbrowski, J. Serwatowski, A. Sporzyński, J. Chem. Eng. Data, 1997, 42, 1111-1115; (f) M. Dąbrowski, J. Serwatowski, A. Sporzyński, Pol. J. Chem., 1998, 72, 2423-2431.
10- A. Adamczyk-Woźniak, I. Madura, A. Pawełko, A. Sporzyński, A. Żubrowska, J. Żyła, Cent. Eur. J. Chem., 2011, 9, 199-205.

11- P. Kurach, S. Luliński, J. Serwatowski, Eur. J. Org. Chem., 2008, 18, 3171-3178.

12- A. Adamczyk-Woźniak, Z. Brzózka, M. Dąbrowski, I. D. Madura, R. Scheidsbach, E. Tomecka, K. Żukowski, A. Sporzyński, J. Mol. Struct., 2013, 1035, 190-197.

13- T. Hofman, M. Reda and M. Gliński, Fluid Phase Equil., 2013, 356, 271-276.

14- C. Achard, M. Jaoui, M. Schwing and M. Rogalski, J. Chem. Eng. Data 1996, 41, 504-507.

15- W. A. Marinaro, L.J. Schieber, E.J. Munson, V.W. Day and V. J. Stella, J. Pharm. Sci., 2012, 1010, 3190-3198.

16- A. Matuszewska, M. Uchman, A. AdamczykWoźniak, A. Sporzyński, S. Pispas, L. Kovacik, M. Stepanek, Biomacromolecules, 2015, 16, 3731-3739. 